\title{
STUDI KOMPARASI BASE SHEAR PADA GEDUNG MENGGUNAKAN BASE ISOLATOR DAN NON BASE ISOLATOR
}

\author{
Ahmad Ridho Siagian ${ }^{1)}$, Wesli $^{2)}$, Yovi Chandra ${ }^{3)}$, Said Jalalul Akbar ${ }^{4)}$ \\ Jurusan Teknik Sipil,Universitas Malikussaleh \\ email: ahmadridhosiagian@gmail.com ${ }^{1)}$,wesli@unimal.ac.id ${ }^{2}$, \\ yovicivil@gmail.com ${ }^{3)}$,jaakidani@gmail.com ${ }^{4)}$ \\ DOI: http://dx.doi.org/10.29103/tj.v7i2.134
}

\begin{abstract}
Abstrak
Perencanaan struktur gedung di Indonesia masih minim dalam penggunaan base isolator pada wilayah gempa kuat seperti Aceh. Penelitian ini mengkombinasikan antara base isolator dan Sistem Rangka Pemikul Momen Khusus (SRPMK) sebagai sistem penahan gaya gempa di wilayah gempa kuat, dengan tujuan untuk mengetahui besarnya perbandingan respon gempa struktur fixed base SRPMK dan struktur SRPMK base isolator pada bangunan tingkat 10. Kedua struktur di analisis dengan spectrum respon dan data gempa yang digunakan adalah data gempa kota Banda Aceh dengan bantuan program Extended Three Dimensional Analysis of Buliding Systems (ETABS) 2016. Respon struktur yang ditinjau adalah gaya geser dasar (base shear), waktu getar alami, perpindahan (displacement), simpangan antar lantai (interstory drift) dan kapasitas penampang kolom tepi dan tengah pada struktur base isolator SRPMK. Dari hasil penelitian diperoleh gaya geser dasar struktur fixed base sebesar $9677,44 \mathrm{kN}$ arah $\mathrm{x}$ dan $9649,26 \mathrm{kN}$ arah y sedangkan struktur base isolator $5871,16 \mathrm{kN}$ arah $\mathrm{x}$ dan $5854,27 \mathrm{kN}$ arah $\mathrm{y}$, hasil waktu getar alami struktur fixed base sebesar 1,178 detik dan struktur base isolator 2,277 detik, dan simpangan antar lantai paling besar terletak di lantai 2 struktur base isolator yaitu $18,948 \%$ mereduksi simpangan antar lantai fixed base dan struktur memenuhi peraturan SNI 03-1726-2012 untuk penggunaan isolasi yaitu 46,51 mm. Kapasitas penampang kolom struktur fixed base pada lokasi pinggir yaitu 0,292 dan 0,427 pada lokasi tengah sedangkan nilai kapasitas penampang kolom struktur base isolator pada lokasi pinggir yaitu 0284 dan 0,374 pada lokasi tengah. Berdasarkan hasil yang diperoleh bahwa penggunaan base isolator dapat mereduksi gaya geser arah x mencapai $40 \%$ dan arah $\mathrm{y}$ mencapai $39 \%$, kemudian dapat memperpanjang waktu getar alami struktur bangunan dua kali. Hal ini menyebabkan gaya gempa yang bekerja semakin kecil dan dimensi kolom dapat diperkecil.
\end{abstract}

Kata kunci: Base share, Base isolator, Analisis respon spektrum

\section{Pendahuluan}

Perencanaan struktur bangunan gedung tahan gempa sangat penting di Indonesia, mengingat sebagian besar wilayahnya terletak dalam wilayah gempa dengan intensitas moderat hingga tinggi. Indonesia terletak pada wilayah pertemuan empat lempeng tektonik utama, yaitu lempeng Australia-India, lempeng Euroasian, lempeng Pasific, dan lempeng Philipina (Teruna, 2005).

Pada tanggal 26 Desember 2004 Aceh diguncang gempa berkekuatan 9,3 skala Richter yang berpusat di Samudra Hindia serta berdampak tsunami yang membunuh ribuan jiwa (Tarigan, 2005). Aceh digolongkan gempa kuat

Studi Komparasi Base Shear Pada Gedung Menggunakan Base Isolator dan Non Base Isolator - Ahmad Ridho Siagian, Wesli, Yovi Chandra, Said Jalalul Akbar 
berdasarkan peta gempa Indonesia (SNI 03-1726-2012). Saat ini di Negara maju telah dikembangkan desain struktur tahan gempa dengan sistem isolasi dasar pada bangunan (base isolated structure). Base isolator terdiri dari lapisan-lapisan karet baik karet alam maupun karet sintetis. Kerusakan akibat gaya gempa pada gedung konvensional dicegah dengan memperkuat struktur bangunan terhadap gaya gempa yang bekerja pada gedung tersebut. Namun, hasil ini tidak cukup untuk meminimalisir kerusakan elemen disebabkan adanya geser dasar (base shear) yang besar mengakibatkan terjadi patahan pada tumpuan yang bersifat kaku (Teruna, 2005). Oleh sebab itu, studi ini dilakukan untuk menganalisis pengaruh penggunaan base isolator terhadap gaya geser (base shear) yang dikombinasikan dengan Sistem Rangka Pemikul Momen Khusus (SRPMK) sebagai sistem penahan gaya gempa.

Berdasarkan permasalahan tersebut, maka penelitian ini bertujuan untuk mengetahui besarnya base shear menggunakan base isolator dan non base isolator serta untuk mengetahui besarnya kapasitas kolom pinggir dan tengah menggunakan base isolator dan non base isolator mampu menahan beban horizontal (gaya gempa) dengan analisis beban respon spektrum.

\section{Tinjauan Kepustakaan}

Gempa bumi adalah suatu peristiwa pelepasan energi gelombang seismic yang terjadi secara tiba-tiba. Pelepasan energi ini diakibatkan karena adanya deformasi lempeng tektonik yang terjadi pada kerak bumi (Hartuti, 2009). Pada bangunan tinggi tahan gempa umumnya gaya-gaya pada kolom cukup besar untuk menahan beban gempa yang terjadi sehingga perlu menggunakan elemen-elemen struktur elastis berupa base isolator untuk menahan kombinasi gaya geser, momen, gaya aksial yang timbul akibat beban gempa.

\subsection{Geser Dasar Seismik}

Beban geser dasar statik ekivalen, meskipun sifatnya statik, namun tidak diperoleh murni dari prinsip statik, tetapi sudah memperhitungkan prinsip-prinsip dinamik (Mulia, 2011). Berdasarkan (SNI 03-1726-2012) menjelaskan bahwa geser dasar seismik V, dalam arah yang ditetapkan harus ditentukan sesuai persamaan 1:

$$
V=C s \cdot W
$$

Keterangan:

$\mathrm{C}_{\mathrm{s}}$ : koefisien respons seismik

$\mathrm{W}$ : berat seismik efektif

\subsection{Waktu getar alami fundamental struktur gedung}

Periode getar $\mathrm{T}$ adalah waktu yang diperlukan untuk menempuh satu putaran lengkap dari suatu getaran ketika terganggu dari posisi keseimbangan statis dan kembali ke posisi aslinya. Semakin besar waktu periode getar alami fundamental pada struktur gedung maka semakin kecil pula gaya gempa yang diterima struktur gedung tesebut. Perioda fundamental pendekatan Ta (detik), harus ditentukan dari persamaan 2:

$$
T a=C t \cdot h_{n}^{x}
$$


Keterangan:

$\mathrm{h}_{\mathrm{n}}$ : ketinggian struktur $(\mathrm{m})$, di atas dasar sampai tingkat tertinggi struktur, dan koefisien Ct dan x ditentukan dari Tabel 1.

Sebagai alternatif, diijinkan untuk menentukan perioda fundamental pendekatan Ta (detik), dari persamaan berikut untuk struktur dengan ketinggian tidak melebihi 12 tingkat di mana sistem penahan gaya gempa terdiri dari rangka penahan momen beton atau baja keseluruhan dan tinggi tingkat paling sedikit $3 \mathrm{~m}$ :

$$
T a=0,1 . N
$$

Keterangan:

$\mathrm{N}$ : jumlah tingkat

Tabel 1 Nilai parameter perioda pendekatan $C_{t}$ dan $x$

\begin{tabular}{|l|c|c|}
\hline \multicolumn{1}{|c|}{ Tipe Struktur } & $C_{t}$ & $x$ \\
\hline $\begin{array}{l}\text { Sistem rangka pemikul momen di mana rangka memikul 100 persen } \\
\text { gaya gempa yang disyaratkan dan tidak dilingkupi atau } \\
\text { dihubungkan dengan komponen yang lebih kaku dan akan } \\
\text { mencegah rangka dari defleksi jika dikenai gaya gempa }\end{array}$ & & \\
\hline Rangka baja pemikul momen & 0,0724 & 0,8 \\
\hline Rangka beton pemikul momen & 0,0466 & 0,9 \\
\hline Rangka baja dengan bresing eksentris & 0,0731 & 0,75 \\
\hline Rangka baja dengan bresing terkekang terhadap tekuk & 0,0731 & 0,75 \\
\hline Semua sistem struktur lainnya & 0,0488 & 0,75 \\
\hline
\end{tabular}

Sumber: (SNI 03-1726-2012)

\subsection{Simpangan (Drift) Akibat Gaya Gempa}

Simpangan (drift) adalah sebagai perpindahan lateral relative antara dua tingkat bangunan yang berdekatan atau dapat dikatakan simpangan mendatar tiaptiap tingkat bangunan (horizontal story to story deflection). Simpangan lateral dari suatu sistem struktur akibat beban gempa sangat penting yang dilihat dari tiga pandangan yang berbeda (Ismail, 2012).

1. Kestabilan struktur (structural stability)

2. Kesempurnaan arsitektural (architectural integrity) dan potensi kerusakan bermacam-macam komponen bukan struktur

3. Kenyamanan manusia (human comfort), sewaktu terjadi gempa bumi dan sesudah bangunan mengalami gerakan gempa.

\subsection{Penentuan Simpangan Antar Lantai}

Berdasarkan (SNI 03-1726-2012), penentuan simpangan antar lantai tingkat desain $(\Delta)$ harus dihitung sebagai perbedaan defleksi pada pusat massa di tingkat teratas dan terbawah. Defleksi merupakan perpindahan (translasi/rotasi) dari suatu titik tertentu sebuah struktur akibat adanya gaya dari luar maupun dari dalam. Defleksi pusat massa di tingkat $(\delta x)(\mathrm{mm})$ sesuai dengan persamaan 4:

$$
\delta x=\frac{C d x \cdot \delta e}{I e}
$$

Studi Komparasi Base Shear Pada Gedung Menggunakan Base Isolator dan Non Base Isolator - Ahmad Ridho Siagian, Wesli, Yovi Chandra, Said Jalalul Akbar 
Keterangan

$\mathrm{Cd}=$ faktor amplifikasi defleksi

$\Delta \mathrm{xe}=$ defleksi pada lokasi yang disyaratkan pada pasal ini yang ditentukan dengan analisis elastic

Ie $=$ faktor keutamaan gempa

Rasio simpangan antar lantai ditentukan dari persamaan 5:

$$
R S A L=\frac{\Delta}{L i}
$$

Keterangan:

RSAL $=$ Rasio Simpangan Antar Lantai

$\Delta \quad=$ simpangan antar lantai

Li = tinggi bangunan

\subsection{Batasan Simpangan Antar Lantai Tingkat}

Simpangan antar lantai maksimum struktur di atas sistem isolasi tidak boleh melebihi $\Delta=0,015 \mathrm{~h}_{\mathrm{sx}}$ sesuai (SNI 03-1726-2012) pasal 12.5.6. Simpangan antar lantai harus dihitung berdasarkan persamaan 4 dengan faktor $\mathrm{C}_{\mathrm{d}}$ dari sistem isolasi sama dengan faktor $\mathrm{R}$ yang ditentukan.

Untuk sistem penahan gaya gempa yang terdiri dari hanya rangka momen pada struktur yang dirancang untuk kategori desain seismik D, E, atau F, simpangan antar lantai tingkat desain $(\Delta)$ tidak boleh melebihi $\Delta_{\mathrm{a}} / \rho$ untuk semua tingkat. $\rho$ harus ditentukan sesuai dengan faktor redundansi kategori desain seismik D sampai F yaitu sebesar 1,3.

\subsection{Sistem Rangka Pemikul Momen}

(SNI 03-1726-2012) menjelaskan sistem rangka pemikul momen merupakan sistem struktur yang pada dasarnya memiliki rangka ruang pemikul beban gravitasi secara lengkap, sedangkan beban lateral yang diakibatkan oleh gempa dipikul oleh rangka pemikul momen lentur. Sistem ini terbagi menjadi 3, yaitu:

1. SRPMB (Sistem Rangka Pemikul Momen Biasa);

2. SRPMM (Sistem Rangka Pemikul Momen Menengah);

3. SRPMK (Sistem Rangka Pemikul Momen Khusus).

\subsection{Analisa Ragam Respon Spektrum}

Analisa Respons Spektrum adalah suatu spektrum yang disajikan dalam bentuk grafik/plot antara periode getar struktur T versus respon-respon maksimum berdasarkan rasio redaman dan gempa teretentu.

Berdasarkan (SNI 03-1726-2012) suatu cara analisis untuk menentukan respons dinamik struktur bangunan gedung tiga dimensi yang berperilaku elastik penuh terhadap pengaruh suatu gempa melalui suatu metoda analisis yang dikenal dengan analisis ragam spektrum respons.

\section{Metode Penelitian}

\subsection{Tahapan Pelaksanaan Penelitian}

Secara umum tahapan penelitian ini meliputi pengumpulan informasi, input data, dan analisa data. Pada tahap pengumpulan informasi, penelitian ini dimulai 
dengan studi literatur yang dilanjutkan dengan pemodelan struktur pada program ETABS 2016. Kemudian input respon gempa dengan data respon spektrum kota Banda Aceh berupa percepatan gerakan tanah akibat gempa serta dilakukan proses analisis gaya gempa dengan menggunakan metode Analisis Respon Spektrum dengan fungsi bangunan sebagai gedung apartemen. Input data dilakukan proses priliminary penampang balok, kolom, dan pelat lantai, kemudian dilanjutkan dengan analisis respon spektrum untuk mengetahui nilai yang diperlukan berupa base shear, waktu getar alami, displacement, interstory drift, dan kapasitas penampang kolom tepi dan tengah. Semua hasil tersebut harus dicek kembali sesuai dengan batasan yang telah disyaratkan pada SNI 03-1726-2012.

\subsection{Metode Pengumpulan Data}

Pengumpulan data bersumber dari buku referensi dan jurnal yang berkaitan dengan topik yang dibahas. Berdasarkan metode pengumpulan data digolongkan kedalam jenis data sekunder terdiri dari:

\section{a. Geometri Model}

Struktur yang akan dilakukan pemodelan dalam penelitian ini adalah model struktur portal tiga dimensi sepuluh tingkat terdiri atas model fixed base SRPMK dan SRPMK dengan base isolator. Untuk keperluan analisa diperlukan sejumlah input data dengan asumsi desain untuk struktur beton bertulang menggunakan SRPMK sebagai sistem penahan gaya gempa pada struktur yang memiliki fungsi sebagai gedung apartemen. Struktur gedung tersebut terdiri dari sepuluh lantai yang berdiri pada lapisan tanah keras (SC) dengan bentuk bangunan simetris.

\section{b. Denah Bangunan}

Denah lantai 1 apartemen ini berisi ruang tunggu untuk para konsumen dan pengunjung yang dilengkapi dengan ruangan para staf apartemen serta akses naik turun berupa tangga dan lift pada koridor apartemen tersebut seperti diperlihatkan pada gambar 1

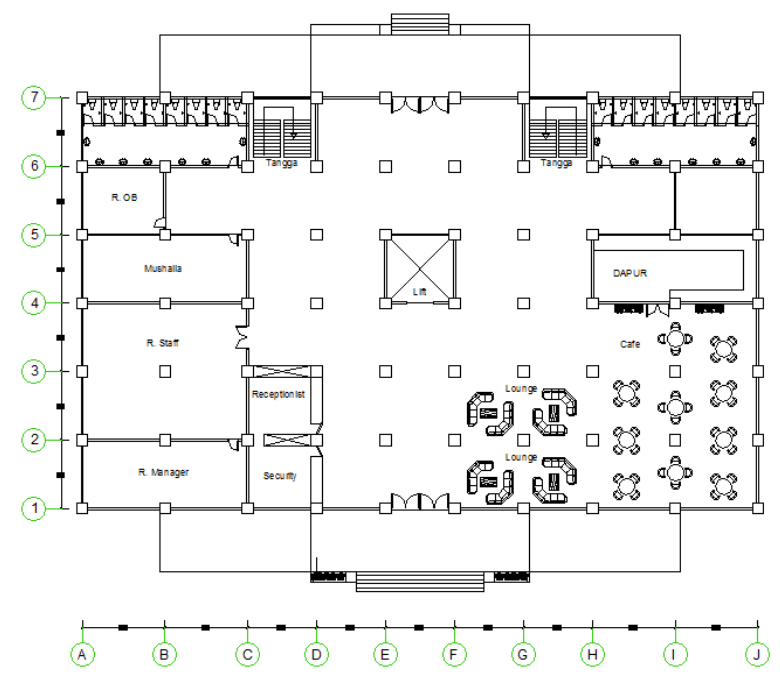

Gambar 1 Denah apartemen lantai 1 


\section{c. Propertis Bangunan}

Propertis elemen balok-kolom terdiri rincian nilai dimensi penampang struktur bangunan yang direncanakan serta keterangan panjang pada balok dan tinggi pada kolom. Selengkapnya diperlihatkan pada Tabel 2.

Tabel 2 Properties Elemen Struktur Balok dan kolom yang digunakan

\begin{tabular}{|c|c|c|c|c|c|c|c|}
\hline \multirow[t]{2}{*}{ No } & \multirow[t]{2}{*}{ Lantai } & \multirow{2}{*}{$\begin{array}{l}\text { Balok dan } \\
\text { kolom Beton } \\
\text { Bertulang }\end{array}$} & \multicolumn{2}{|c|}{$\begin{array}{c}\text { Dimensi } \\
\text { Penampang } \\
\text { balok }\end{array}$} & \multicolumn{2}{|c|}{$\begin{array}{c}\text { Dimensi } \\
\text { Penampang } \\
\text { kolom }\end{array}$} & \multirow{2}{*}{$\begin{array}{l}\text { Tinggi } \\
\text { kolom } \\
(\mathrm{m})\end{array}$} \\
\hline & & & $\mathrm{b}(\mathrm{m})$ & $\mathrm{h}(\mathrm{m})$ & $\begin{array}{c}\mathrm{b} \\
(\mathrm{m})\end{array}$ & $\mathrm{h}(\mathrm{m})$ & \\
\hline 1 & Lantai 1 & BI dan K1 & 0,5 & 0,7 & 0,8 & 0,8 & 4 \\
\hline 2 & Lantai 2 & $\mathrm{~B} 2$ dan $\mathrm{K} 2$ & 0,5 & 0,7 & 0,8 & 0,8 & 4 \\
\hline 3 & Lantai 3 & B3 dan K3 & 0,5 & 0,7 & 0,8 & 0,8 & 4 \\
\hline 4 & Lantai 4 & B4 dan K4 & 0,5 & 0,7 & 0,8 & 0,8 & 4 \\
\hline 5 & Lantai 5 & B5 dan K5 & 0,5 & 0,7 & 0,8 & 0,8 & 4 \\
\hline 6 & Lantai 6 & B6 dan K6 & 0,5 & 0,7 & 0,8 & 0,8 & 4 \\
\hline 7 & Lantai 7 & B7 dan K7 & 0,5 & 0,7 & 0,8 & 0,8 & 4 \\
\hline 8 & Lantai 8 & $\mathrm{~B} 8$ dan $\mathrm{K} 8$ & 0,5 & 0,7 & 0,8 & 0,8 & 4 \\
\hline 9 & Lantai 9 & B9 dan K9 & 0,5 & 0,7 & 0,8 & 0,8 & 4 \\
\hline 10 & Lantai 10 & RB10 dan K10 & 0,5 & 0,7 & 0,8 & 0,8 & 4 \\
\hline
\end{tabular}

\section{d. Base isolator}

Permodelan struktur base isolator dilakukan dengan menggunakan software ETABS dengan pemodelan pada bangunan SRPMK. Bangunan yang menggunakan base isolator memiliki perpindahan yang lebih besar dari pada bangunan normal. Dalam penelitian analisa respon gempa akan digunakan Type Base Isolator berdasarkan Design chracteristic of high damping rubber bearing, bridgestone, jepang 2012. Setelah total massa bangunan diketahui yaitu $126779,3 \mathrm{kN}$, maka tipe base isolator yang akan digunakan adalah seperti pada Tabel 3 dan Tabel 4.

Tabel 3 tipe dan spesifikasi base isolator yang digunakan

\begin{tabular}{|c|c|c|c|c|c|}
\hline Tipe & $\begin{array}{c}\text { Diameter } \\
(\mathrm{mm})\end{array}$ & $\begin{array}{c}\text { Aksial } \\
\text { load } \\
(\mathrm{KN})\end{array}$ & $\begin{array}{c}\text { Shear } \\
\text { Modulus } \\
\left(\mathrm{N} / \mathrm{mm}^{2}\right)\end{array}$ & $\begin{array}{c}\text { Post Yield } \\
\text { Stiffness } \\
(\gamma=100 \%) \\
\left(\mathrm{x} 10^{3} \mathrm{KN} / \mathrm{m}\right.\end{array}$ & $\begin{array}{c}\text { Equivalent } \\
\text { Damping } \\
\text { Ratio }\end{array}$ \\
\hline HH065X4S & 650 & 1830 & 0.392 & 0.389 & 0.240 \\
\hline
\end{tabular}

Tabel 4 Parameter mekanis HDRB berdasarkan data supplier Bridgestone pada kondisi 100\% shear strain (Bridgestone Corporation, 2012)

\begin{tabular}{|l|c|c|}
\hline \multirow{2}{*}{\multicolumn{1}{c|}{ Properti Mekanis }} & $\begin{array}{c}\text { Spesifikasi HDRB (Bridgestone - } \\
\text { 100\% Shear strain) }\end{array}$ \\
\cline { 2 - 3 } & \multicolumn{2}{|c|}{ HHO65X4S } \\
\hline Kekakuan Awal & $\mathrm{KN} / \mathrm{m}$ & 3890 \\
\hline Kekakuan Paska Leleh & $\mathrm{KN} / \mathrm{m}$ & 389 \\
\hline Kuat Leleh & $\mathrm{KN}$ & 56 \\
\hline Kekakuan Efektif & $\mathrm{KN} / \mathrm{m}$ & 657 \\
\hline Rasio Redaman efektif & $\%$ & 24 \\
\hline
\end{tabular}

Studi Komparasi Base Shear Pada Gedung Menggunakan Base Isolator dan Non Base Isolator - Ahmad Ridho Siagian, Wesli, Yovi Chandra, Said Jalalul Akbar 
4. Hasil dan Pembahasan

4.1 Gaya Geser (Base Shear)

Salah satu perbedaan mendasar antara struktur fixed base dan struktur terisolasi adalah gaya geser dasar (base shear). Beban geser dasar statik ekivalen, meskipun sifatnya statik, namun tidak diperoleh murni dari prinsip statik, tetapi sudah memperhitungkan prinsip-prinsip dinamik.

\section{A. Base shear fixed base SRPMK}

Hasil analisis base shear menggunakan ETABS 2016 untuk struktur SRPMK diperlihatkan pada Tabel 5.

Tabel 5 Hasil gaya geser (base shear) struktur fixed base SRPMK

\begin{tabular}{|c|c|}
\hline Arah & Base Shear (kN) \\
\hline Memanjang (x) & 9677,44 \\
\hline Melintang (y) & 9649,26 \\
\hline
\end{tabular}

Tabel 5 menunjukkan nilai gaya geser dasar arah memanjang (x) dan arah melintang (y) pada bangunan fixed base SRPMK. Hasil penelitian ini diperoleh bahwa nilai gaya geser dasar fixed base SRPMK arah memanjang (x) 9677,44 $\mathrm{kN}$ dan arah melintang (y) 9649,26 kN.

\section{B. Base shear base isolator SRPMK}

Hasil analisis base shear menggunakan ETABS 2016 untuk struktur base isolator SRPMK diperlihatkan pada Tabel 6.

Tabel 6 Hasil gaya geser (base shear) struktur base isolator SRPMK

\begin{tabular}{|c|c|}
\hline Arah & Base Shear $(\mathrm{kN})$ \\
\hline Memanjang (x) & 5871,16 \\
\hline Melintang (y) & 5854,27 \\
\hline
\end{tabular}

Tabel 6 menunjukkan nilai gaya geser dasar arah memanjang (x) dan arah melintang (y) pada bangunan base isolator SRPMK. Hasil penelitian ini diperoleh bahwa nilai gaya geser dasar base isolator SRPMK arah memanjang (x) $5871,16 \mathrm{kN}$ dan arah melintang (y) 5854,27 kN. Hasil analisis perbandingan nilai base shear fixed base SRPMK dan SRPMK base isolator, didapatkan nilai rata-rata reduksi gaya geser pada arah memanjang mencapai $40 \%$ dan arah melintang $39 \%$.

\subsection{Periode Getar Alami Struktur}

Salah satu perbedaan mendasar antara struktur fixed base dan struktur terisolasi adalah periode getarnya. Periode adalah besarnya waktu yang dibutuhkan untuk mencapai satu getaran. Periode alami struktur perlu diketahui agar resonansi pada struktur dapat dihindari.

\section{A. Perioda fixed base SRPMK}

Hasil analisis modal menggunakan ETABS 2016 untuk struktur SRPMK diperlihatkan pada Tabel 7. 
Tabel 7 Hasil Analisis Modal Struktur Fixed base SRPMK

\begin{tabular}{|c|c|c|}
\hline Deformed shape & Mode & Perioda $(\mathbf{s e c})$ \\
\hline Modal & 1 & 1,178 \\
\hline Modal & 2 & 1,175 \\
\hline Modal & 3 & 1,104 \\
\hline Modal & 4 & 0,381 \\
\hline Modal & 5 & 0,38 \\
\hline Modal & 6 & 0,358 \\
\hline Modal & 7 & 0,218 \\
\hline Modal & 8 & 0,217 \\
\hline Modal & 9 & 0,206 \\
\hline Modal & 10 & 0,132 \\
\hline Modal & 11 & 0,131 \\
\hline Modal & 12 & 0,118 \\
\hline
\end{tabular}

Hasil analisis modal menunjukkan bahwa mode pertama struktur fixed base SRPMK adalah translasi arah melintang (y) dengan perioda struktur 1,178 detik. Mode kedua adalah translasi arah memanjang (x) dengan perioda struktur 1,175 detik.

\section{B. Perioda base isolator SRPMK}

Hasil analisis modal menggunakan ETABS 2016 untuk struktur SRPMK dengan base isolator diperlihatkan pada Tabel 8.

Tabel 8 Hasil Analisis Modal Struktur SRPMK Base isolator

\begin{tabular}{|c|c|c|}
\hline Deformed shape & Mode & $\begin{array}{c}\text { Perioda } \\
\text { (sec) }\end{array}$ \\
\hline Modal & 1 & 2,277 \\
\hline Modal & 2 & 2,272 \\
\hline Modal & 3 & 2,148 \\
\hline Modal & 4 & 0,55 \\
\hline Modal & 5 & 0,543 \\
\hline Modal & 6 & 0,511 \\
\hline Modal & 7 & 0,276 \\
\hline Modal & 8 & 0,275 \\
\hline Modal & 9 & 0,26 \\
\hline Modal & 10 & 0,166 \\
\hline Modal & 11 & 0,165 \\
\hline Modal & 12 & 0,14 \\
\hline
\end{tabular}

Hasil analisis modal menunjukkan bahwa mode pertama struktur SRPMK dengan base isolator adalah translasi arah melintang (y) dengan perioda sebesar 2,277 detik. Mode kedua adalah translasi arah memanjang (x) dengan perioda 2,272 detik. Dengan adanya isolator, maka gaya gempa yang mengenai struktur akan terlebih dahulu bekerja pada isolator kemudian baru diteruskan 
ke struktur atas. Peningkatan perioda struktur mencapai 2 kali lebih besar dari bangunan fixed base dan menyebabkan gaya gempa yang bekerja pada bangunan akan menjadi lebih kecil.

\subsection{Kapasitas Penampang Kolom}

Hasil analisis program ETABS 2016 menunjukkan nilai kapasitas kolom struktur fixed base SRPMK dan base isolator SRPMK. Perbandingan antara struktur kolom pinggir dan struktur kolom tengah pada kedua struktur dapat dilihat pada tabel di bawah ini yang menjadi fokus tinjauan untuk kolom pinggir yaitu tinjauan 1 dan untuk kolom tengah yaitu tinjauan 2 yang dimulai dari kolom lantai 1 sampai kolom lantai atap seperti diperlihatkan pada Tabel 9.

Tabel 9 Kapasitas penampang kolom fixed base SRPMK

\begin{tabular}{|c|c|c|c|}
\hline Unit & Lantai & $\begin{array}{c}\text { Rasio Kolom } \\
\text { Pinggir }\end{array}$ & $\begin{array}{c}\text { Rasio Kolom } \\
\text { Tengah }\end{array}$ \\
\hline 1945 & Atap & 0,120 & 0,127 \\
\hline 1752 & 9 & 0,190 & 0,206 \\
\hline 1559 & 8 & 0,187 & 0,289 \\
\hline 1366 & 7 & 0,201 & 0,326 \\
\hline 1173 & 6 & 0,224 & 0,356 \\
\hline 980 & 5 & 0,246 & 0,371 \\
\hline 787 & 4 & 0,266 & 0,392 \\
\hline 594 & 3 & 0,284 & 0,418 \\
\hline 352 & 2 & 0,292 & 0,427 \\
\hline 448 & 1 & 0,264 & 0,371 \\
\hline
\end{tabular}

Dari Tabel 9 dapat dilihat bahwa kapasitas kolom fixed base SRPMK yang terbesar yaitu pada lantai dua dengan nilai 0,292 pada kolom pinggir dan pada kolom tengah kapasitas kolom terbesar yaitu pada lantai dua dengan nilai 0,427 .

Tabel 10 Kapasitas penampang kolom base isolator SRPMK

\begin{tabular}{|c|c|c|c|}
\hline Unit & Lantai & $\begin{array}{c}\text { Rasio Kolom } \\
\text { Pinggir }\end{array}$ & $\begin{array}{c}\text { Rasio Kolom } \\
\text { Tengah }\end{array}$ \\
\hline 1945 & Atap & 0,107 & 0,125 \\
\hline 1752 & 9 & 0,161 & 0,174 \\
\hline 1559 & 8 & 0,181 & 0,175 \\
\hline 1366 & 7 & 0,177 & 0,193 \\
\hline 1173 & 6 & 0,171 & 0,222 \\
\hline 980 & 5 & 0,167 & 0,241 \\
\hline 787 & 4 & 0,171 & 0,249 \\
\hline 594 & 3 & 0,180 & 0,258 \\
\hline 352 & 2 & 0,196 & 0,296 \\
\hline 448 & 1 & 0,284 & 0,374 \\
\hline
\end{tabular}

Dari Tabel 10 dapat dilihat bahwa kapasitas kolom base isolator SRPMK yang terbesar yaitu pada lantai dasar dengan nilai 0,284 pada kolom pinggir dan 
pada kolom tengah kapasitas kolom terbesar yaitu pada lantai dasar dengan nilai 0,427. Jadi, dapat disimpulkan kapasitas penampang kolom yang lebih besar pada struktur ini adalah pada lokasi tengah dikarenakan lebih besar menahan gaya yang bekerja pada struktur dan kapasitas penampang kolom pada struktur base isolator lebih kecil dibandingkan fixed base SRPMK karena sudah dibantu oleh sistem isolasi seismik untuk mengisolasi gaya gempa yang terjadi sebelum masuk kedalam struktur tersebut.

\section{Kesimpulan dan Saran}

\subsection{Kesimpulan}

Berdasarkan nilai yang diperoleh bahwa penggunaan base isolator dapat mereduksi gaya geser arah x mencapai $40 \%$ dan arah y mencapai 39\%, kemudian dapat memperpanjang waktu getar alami struktur bangunan dua kali. Kapasitas penampang kolom pada struktur base isolator SRPMK lebih kecil dibandingkan fixed base SRPMK karena sudah dibantu oleh sistem isolasi seismik untuk mengisolasi gaya gempa yang terjadi sebelum masuk kedalam struktur gedung tersebut sehingga dimensi kolom pada base isolator SRPMK dapat diperkecil.Jadi dapat disimpulkan bahwa penggunaan base isolator pada wilayah rawan gempa seperti Aceh sangat efektif mereduksi beban gempa yang terjadi pada bangunan dan dimensi kolom dapat diperkecil dalam perencanaannya.

\subsection{Saran}

Seismic base isolation terbukti dapat meredam gaya gempa dan memperkecil gaya dalam yang bekerja pada struktur dan pondasi. Seharusnya teknologi ini direncanakan oleh para Konsultan di Aceh dikarenakan Aceh merupakan daerah rawan gempa.

\section{Daftar Kepustakaan}

Ismail, Febrin Anas, 2012, Pengaruh Penggunaan Seismic Base Isolation System Terhadap Respons Struktur Gedung Hotel Ibis Padang, Jurnal Rekayasa Sipil 8 (1):45-60.

Standar Nasional Indonesia, (SNI 03-1726-2012), 2012, Tata Cara Perencanaan Ketahanan Gempa Untuk Struktur Bangunan Gedung Dan Non Gedung, Badan Standardisasi Nasional, Puslitbang pemukiman, Bandung.

Tarigan, Johannes, 2005, Kerusakan Akibat Tsunami Dan Gempa Northen Sumatra 26 Desember 2004 Terhadap Banda Aceh Dan Sirombu Nias Barat, Jurnal Sistem Teknik Industri 6 (3):180-89.

Teruna, Daniel, 2005, Analisis Respon Bangunan Dengan Base Isolator Akibat Gaya Gempa, Jurnal Sistem Teknik Industri 6 (4):58-63.

Teruna, Daniel Rumbi, and Hendrik Singarimbun, 2010, Analisis Response Bangunan ICT Universitas Syiah Kuala Yang Memakai Slider Isolator, Seminar Dan Pameran HAKI. 